\title{
Experience with intravenous immunoglobulin in myasthenia gravis: a review
}

\author{
Gilles Edan, Frank Landgraf
}

Myasthenia gravis is an autoimmune disorder of neuromuscular transmission associated with a deficiency of acetylcholine receptors. Current therapies that influence the immune response include: thymectomy, corticosteroids, non steroidal immunosuppression and plasmapheresis. The management of patients with myasthenia gravis, usually involves a combination of these therapies to produce an adequate response. ${ }^{1-3}$ Such a combination exposes the patient to a significant level of toxicity. However, treatment with intravenous immunoglobulin (IVIg) has shown less side effects and should therefore be considered a promising therapy in the treatment of myasthenia gravis.

IVIg has been studied in a number of trials over the past ten years. These open trials were non blind, uncontrolled and of limited value. Patient populations were small and heterogeneous for: previous treatment, inclusion criteria and duration of disease. We reviewed six open clinical trials ${ }^{4-9}$ (table) which used the same treatment schedule $(0 \cdot 4$ $\mathrm{gr} / \mathrm{kg} / \mathrm{d}$ for five days) and attempted to draw some conclusions.

Overall the studies showed similar findings. A total of 76 patients were investigated, the majority of whom were severely affected. The percentage of positive responses was $70-100 \%$, with a mean of $79 \%$. Most patients were receiving concomitant medication which was held constant before and during IVIg treatment. A large majority were treated with corticosteroids, except for those in the study by Gajdos. ${ }^{4}$ The minority received azathioprine alone or with corticosteroids. Thymectomy was performed on most patients before IVIg treatment. Immunoglobulin was given during different clinical stages of the disease. In the series by Arsura $^{10}$ and in Cosi's study, ${ }^{8}$ patients were treated during an acute onset or in acute relapse. In Gajdos, ${ }^{4}$ Ippoliti ${ }^{5}$ and for part of Cosi's ${ }^{8}$ series, the patients were treated with IVIg in a static phase of the disease that lasted from two to six months. There was no significant difference in improvement between chronic-static and acute cases, as improvement was observed in more than $70 \%$ of both groups. In the responding patients, there was an improvement within three weeks from the start of therapy. Four of the five patients of Gajdos et al improved significantly between days 10 and 15 and remained stable up to day 25 . In the study by Ippoliti, six patients improved within three weeks and five remained so on day 60 . In the study by Arsura, improvement began from one to nine days (median 4) after the start of IV Immunoglobulin therapy with sustained improvement lasting from 19 to 120 days (median 41 ). In the study by Cosi, a definite improvement was recorded at day six in 17 patients, at day 12 in 26 patients and persisted until day 60 in 21 patients. In the study by Evoli, eight patients showed a definite improvement that was seen within three to 20 days after the start of IVIg and lasted 30-120 days. It appears therefore that IVIg can produce a rapid improvement in symptoms, lasting for approximately 40-60 days.

Arsura et $a l^{10}$ administered repeated courses of intravenous immunoglobulin to nine patients at the onset of an exacerbation of generalised myasthenia gravis. These patients were selected because they had initially responded to IVIg. They received from two to five courses of IVIg each with a total of 23 courses. A satisfactory response was seen after 20 courses. Improvement in muscle strength began from one to seven days (median 4) after the start of IVIg and peaked at median day 8 . Sustained improvement per course lasted a median of 90 days: 45 days for the first course, 180 days for the second and

Clinical trials of intravenous immunoglobulin $(0 \cdot 4 \mathrm{gr} / \mathrm{Kg} / \mathrm{d}$ for five days) in myasthenia gravis

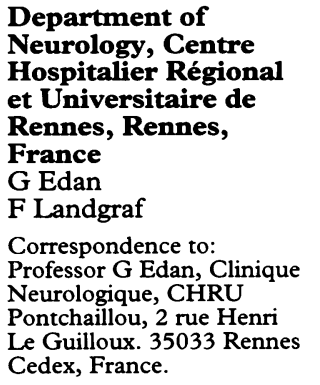

Department of Hospitalier Régiona et Universitaire de Rennes, Rennes, France

F Landgra

Correspondence to: Professor G Edan, Clinique Pontchaillou, 2 rue Henri Le Guilloux. 35033 Rennes Cedex, France.

\begin{tabular}{|c|c|c|c|c|c|c|}
\hline Reference & $\begin{array}{l}\text { Number of } \\
\text { patients }\end{array}$ & $\begin{array}{l}\text { Cocomittant } \\
\text { medication }\end{array}$ & $\begin{array}{l}\text { Clinical } \\
\text { stage }\end{array}$ & $\begin{array}{l}\text { Number of } \\
\text { improvement }\end{array}$ & $\begin{array}{l}\text { Onset of } \\
\text { improvement }\end{array}$ & $\begin{array}{l}\text { Duration of } \\
\text { improvement }\end{array}$ \\
\hline $\begin{array}{l}\text { Gajdos }^{4} \\
\text { Ippoliti }^{5}\end{array}$ & $\begin{array}{l}5 \\
7\end{array}$ & \multirow{8}{*}{$\begin{array}{l}0 \\
\mathrm{P} / \mathrm{AZA} / \mathrm{T} \\
7 \quad 7 \quad 6 \\
\mathrm{P} / \mathrm{T} \\
8 \quad 8 \\
\mathrm{ND} \\
\mathrm{P} / \mathrm{AZA} / \mathrm{T} \\
26 \quad 12 \quad 29 \\
\mathrm{P} / \mathrm{AZA} / \mathrm{T} \\
10 \quad 2 \quad \mathrm{ND} \\
0\end{array}$} & \multirow{2}{*}{$\begin{array}{l}\text { Stable } \\
\text { Sable }\end{array}$} & 4 & \multirow{2}{*}{$\begin{array}{l}10-15 \text { days } \\
\text { ND }\end{array}$} & \multirow{2}{*}{$\begin{array}{l}\text { ND } \\
>60 \text { days }\end{array}$} \\
\hline Ippoliti & 7 & & & & & \\
\hline Arsura ${ }^{6}$ & 12 & & Acute & 11 & 1-9 days & $19-120$ days \\
\hline Cook $^{7}$ & 5 & & \multirow{3}{*}{$\begin{array}{l}\text { NS } \\
\text { Acute / Stable } \\
\quad 11 \quad 26 \\
\text { ND }\end{array}$} & 5 & $0-10$ days & ND \\
\hline $\operatorname{Cosi}^{8}$ & 37 & & & 26 & $6-10$ days & $>60$ days \\
\hline Evoli $^{9}$ & 10 & & & 8 & 3-20 days & $30-120$ days \\
\hline $\begin{array}{l}\text { Our experience } \\
\text { (Edan) }\end{array}$ & 10 & & \multirow[t]{2}{*}{$\begin{array}{cr}\text { Acute/Stable } \\
6\end{array}$} & 7 & 1-7 days & 30 days -2 years \\
\hline Total & 86 & & & $67(78 \%)$ & & \\
\hline
\end{tabular}


90 days for the third. Thus sustained improvements per patient lasted a median of 225 days.

The immediate adverse side effects of IVIg in these series were limited to minor symptoms such as, headaches, pedal oedema, or mild dyspnoea. These effects were seen in less than $10 \%$ of patients and it was not necessary to interrupt their treatment. Aseptic meningitis has recently been reported as a complication of IVIg therapy in the treatment of myasthenia gravis. ${ }^{11}$

Since 1988, we have treated some of our MG patients with IVIg. We have retrospectively selected 10 patients (seven men, three women, median age 53, two of them with thymoma) who were treated at an early stage of the disease (median six months), and who were not taking concomittant immunological medication. We observed similar responses to previous authors for this homogenous group of patients. Seven of 10 patients showed marked improvement, which occurred rapidly within one week and lasted for six to 12 weeks whether the patient was in an acute or stationary phase of the disease.

Our experience enables us to put forward some positive and negative aspects of IVIg treatment in MG. The negative aspects include: the temporary nature of the response, the high cost of the product, and the injection of human blood and the accompanying risk of infection. However, the positive impact of IVIg therapy on MG are evident in the high rate of response, rapid onset of improvement, the lack of recognised short- and long-term toxicity, the reproducibility of the response (the temporary nature of response may be overcome by using repetitive courses) resulting in the reduction of corticosteroid therapy in the majority of patients.

The mechanisms underlying clinical improvement remains obscure, but those that have been proposed include: competition with $\mathrm{AChR} \mathrm{Ab}$ for binding with $\mathrm{AChR}^{12}$; prevention of the attachment of Fc receptorpositive inflammatory cells to $\mathrm{AChR} A b$ bound to motor end plate; an anti-idiotypic effect,,$^{13} 14$ and stimulation of suppression.

There are no firm guidelines for the use of
IVIg in MG. ${ }^{15}$ Controlled, blind studies are needed to evaluate IVIg treatment in the different stages of MG and to compare IVIg therapy with conventional treatment such as: plasma exchange for prethymectomy; and for initiating oral steroid treatment. IVIg should also be evaluated long term, for example in tandem with thymectomy (as two and five years are required to show its efficacy in 50 and $90 \%$ of patients respectively), in addition to corticosteroid therapy, thereby allowing for a reduction in the dose of corticosteroid. Evaluation could also be carried out for the use of IVIg as bridging treatment in the period before the effect of immunosuppressive agents become apparent.

1 Pascuzzi RM, Coslett HB, Johns TR. Long-term cortisteroid treatment of myasthenia gravis: report of 116 patients. Ann Neurol 1984;15:291-8.

2 Verma P, Oger J. Treatment of acquired autoimmune myasthenia gravis: a topic review. Can $\mathcal{f}$ Neurol $\mathrm{Sci}$ 1992;19:360-75.

3 Drachman DB, McIntosh KR, Reim J, Balcer L. Strategies for treatment of myasthenia gravis. Ann NY Acad Sci 1993;681:515-25.

4 Gadjos Ph, Outin H, Elkharrat D, et al. High-dose intravenous gammaglobulin for myasthenia gravis. Lancet 1984;1:406-7.

5 Ippoliti G, Cosi V, Piccolo G, Lombardi M, Mantegaz R. High-dose intravenous gammaglobulin for myasthenia High-dose intravenous gam

6 Arsura EL, Bick A, Brunner NG, Namba T, Grob D. High-dose intravenous immunoglobulin in the management of myasthenia gravis. Arch Inter Med 1986;146: 1365-68.

7 Cook L, Howard JF, Folds JD. Immediate effects of intravenous IgG administration on peripheral blood $B$ and $T$ cells and polymorphonuclear cells in patients with myasthenia gravis. $\mathcal{f}$ Clin Immunol 1988;8(1):23-31.

8 Cosi V, Lombardi M, Piccolo G, Erbetta A. Treatment of myasthenia gravis with high-dose intravenous immunoglobulin. Acta Neurol Scand 1991;84:81-84.

9 Evoli A, Bartoccioni E, Palmisani MT, Provenzano C, Tonali P. IgG Therapy in Myasthenia Gravis Patients. Tonali P. IgG Therapy in Myasthe

10 Arsura EL, Bick A, Brunner NG, Grob D. Effects of Repeated Doses of Intravenous Immunoglobulin in Repeated Doses of Intravenous Immunoglobulin in

11 Meiner Z, Ben-Hur T, River Y, Reches A. Aseptic meningitis as compliation of intravenous immunoglobulin therapy fort Myasthenia Gravis. If Neurol Neurosurg Psychiatry 1993;56(7):830-1.

12 Dwyer JM. Manipulating the Immune System with Immune Globulin. N Engl f Med 1992;2(326):107-16.

13 Zweiman B. Theorical Mechanisms by Which Immunoglobulin Therapy Might Benefit Myasthenia Gravis. Clin Immunol Immunopathol 1989;53:83-91.

14 Ferrero B, Durelli L, Cavallo R, Dutto A, Aimo G, Pecchio F, Bergamasco B. Therapies of Exacerbation of Myasthenia Gravis. The Mechanism of Action of Intravenous High-Dose Immunoglobulin Gann. NY Acad Sci 1933;681;563-6.

15 Arsura EL Experience with Intravenous Immunoglobulin in Myasthenia Gravis Clin Immunol Immunopathol 1989; 53(2):170-9. 